J. Electroanal. Chem., 237 (1987) 237-250

Elsevier Sequoia S.A., Lausanne - Printed in The Netherlands

\title{
THE ACTIVE SURFACE AREA INCREASE OF RHODIUM ELECTRODES THROUGH ELECTROREDUCTION OF OXIDE LAYERS PRODUCED BY FAST PERIODIC POTENTIALS
}

\author{
A.C. CHIALVO *, W.E. TRIACA and A.J. ARVIA \\ Instituto de Investigaciones Fisicoquímicas Teóricas y Aplicadas (INIFTA) ${ }^{\star \star}$, Casilla de Correo 16, \\ Sucursal 4, 1900 La Plata (Argentina)
}

(Received Sth August 1987; in revised form 18th June 1987)

\begin{abstract}
Fast periodic potentials applied to polycrystalline rhodium electrodes in acid and base electrolytes can cause, under certain conditions, the growth of hydrous oxide layers which after their electroreduction yield reproducible electrode surfaces with a large increase in the active surface area. These processes were investigated at $30^{\circ} \mathrm{C}$ by changing systematically the parameters of the perturbing potential including potentiostatic steps. The most suitable conditions for growing oxide layers capable of producing an increase in the rhodium electrode active surface area after their electroreduction correspond to a square wave perturbing potential at $1.8 \mathrm{kHz}$ and a potential window between -0.025 and $2.0 \mathrm{~V}$ (vs. RHE). The processes related to the formation of anodic oxide layers under different experimental conditions are discussed.
\end{abstract}

\section{INTRODUCTION}

Fast periodic potentials in the $0.1-10 \mathrm{kHz}$ frequency range are able to promote important modifications at noble metal electrode surfaces [1]. Depending on how the periodic potential is applied to the electrode, two relevant limiting situations can be accomplished. The first concerns the electrochemical faceting of the electrode surface and the development of a preferred crystallographic orientation implying a negligible increase in the electrode active area [2,3], which, for the case of rhodium, was extensively dealt with in a previous publication [4]. The second comprises significant changes in the active electrode area provoked through the electroformation of a thick oxide layer by means of fast periodic potentials and further single

\footnotetext{
* Present address: PRELINE, Facultad de Ingeniería Química, Universidad Nacional del Litoral, Argentina.

$\star \star$ Facultad de Ciencias Exactas, Universidad Nacional de La Plata.
} 
sweep electroreduction $[5,6]$. This treatment produces no appreciable development of preferred crystallographic orientations. The intriguing property of the increase in active surface area is that for an apparent roughness factor of about $10^{3}$, the resulting electrode surface, as has been observed for platinum, offers particular features such as the absence of an anomalous voltammetric response [7], in contrast with large real area noble metal electrodes produced by conventional metal electrodepositing [8]. Therefore, the management of these two limiting situations for solid electrodes is exceptionally interesting as a rational approach for developing noble metal electrocatalysts [9]. The enhancement of oxide growth at a rhodium surface was studied in a base solution under potential cycling conditions, without considering the corresponding electroreduction process [10].

The present paper deals with the increase in the active surface area of rhodium electrodes produced through the electroreduction of a surface oxide layer formed under fast periodic potentials. In this respect, the importance of rhodium electrocatalysts is well recognized as it arises from the promising results obtained by the application of these electrodes either plain or as alloys in many electrochemical reactions [11-15].

\section{EXPERIMENTAL}

Runs were made in a three-electrode compartment Pyrex glass cell. Polycrystalline (pc) rhodium wires (Johnson Matthey Chem. Co.) of $0.07-0.7 \mathrm{~cm}^{2}$ geometric area previously polished mechanically with alumina $5 \mu \mathrm{m}$ grit were used as the working electrodes. The potential of the working electrode was measured against a RHE in the same electrolyte solution. A large area rhodium counter-electrode was used. The counter-electrode compartment was connected directly to the rest of the cell to minimize the ohmic drop between the electrodes. Runs were made in different electrolytes $\left(1 \mathrm{M} \mathrm{H} \mathrm{SO}_{4}, 1 M \mathrm{HClO}_{4}\right.$ and $\left.1 M \mathrm{NaOH}\right)$ at $30^{\circ} \mathrm{C}$. Solutions were prepared with triply distilled water free of organic impurities.

The following types of experiments were carried out:

(1) Conventional voltammograms at a low potential sweep rate $(0.04 \mathrm{~V} / \mathrm{s} \leqslant v \leqslant$ $0.20 \mathrm{~V} / \mathrm{s}$ ) for both starting pc rhodium electrodes and those resulting after the application of fast periodic potentials as indicated in (2). From the comparison of the corresponding voltammetric responses the modifications in the electrode surface characteristics can be followed.

(2) Application of fast periodic potentials during time $t$ comprising either symmetric repetitive triangular potential sweeps (RTPS) between lower $\left(E_{\mathrm{s}, \mathrm{c}}=0 \mathrm{~V}\right)$ and upper $\left(1.5 \mathrm{~V} \leqslant E_{\mathrm{s}, \mathrm{a}} \leqslant 3.0 \mathrm{~V}\right)$ switching potentials or symmetric repetitive square wave potential signals (RSWPS), from a lower potential value $\left(-0.2 \mathrm{~V} \leqslant E_{1} \leqslant 0.3\right.$ V) up to an upper potential value $\left(1.5 \mathrm{~V} \leqslant E_{\mathrm{u}} \leqslant 3.0 \mathrm{~V}\right)$ to grow an anodic oxide layer on the electrode. The frequency $(f)$ of the periodic potential signal was varied between 0.016 and $6 \mathrm{kHz}$.

(3) Measurements of the electroreduction charges corresponding to the anodic oxide layers formed during the RSWPS treatment were made through integration of the corresponding potentiostatic current transients. 
(4) Combination of linear potential sweeps and potential steps to obtain additional information about the anodic oxide layer produced under constant potential steps higher than $1.5 \mathrm{~V}$.

Most of the experiments were done in $1 \mathrm{M} \mathrm{H}_{2} \mathrm{SO}_{4}$, and occasionally in $1 \mathrm{M}$ $\mathrm{HClO}_{4}$ and $1 \mathrm{M} \mathrm{NaOH}$ to establish the influence of the electrolyte composition on the electrochemical characteristics of the anodic oxide layer grown under controlled potential conditions.

\section{RESULTS}

\section{Voltammetric changes of rhodium electrodes produced by RTPS}

The voltammetric response at $0.04 \mathrm{~V} / \mathrm{s}$ of pc rhodium in $1 M \mathrm{H}_{2} \mathrm{SO}_{4}$ at $30^{\circ} \mathrm{C}$ in the $0-1.25 \mathrm{~V}$ range (Fig. 1a) exhibits the complex electroadsorption/electrodesorption spectra of $\mathrm{H}$-adatoms in the $0-0.30 \mathrm{~V}$ range, the wide current peak related to the electroformation of O-containing surface species in the $0.50-1.25 \mathrm{~V}$ range and the wide electroreduction current peak for the O-containing surface species extending from 0.90 to ca. $0.20 \mathrm{~V}$. This voltammogram coincides with those described more extensively in the literature [16-18] and is presented for the sake of comparison.

A pc rhodium electrode which has been subjected to RTPS in the $100-1000 \mathrm{~V} / \mathrm{s}$ range exhibits a voltammogram in $1 \mathrm{M} \mathrm{H}_{2} \mathrm{SO}_{4}$, at $0.04 \mathrm{~V} / \mathrm{s}$, which differs from that of the blank in two respects: namely, the voltammetric charge and the sharpness and definition of the $\mathrm{H}$-adatom peaks. These changes are very sensitive to the selected values of $E_{\mathrm{s}, \mathrm{c}}, E_{\mathrm{s}, \mathrm{a}}$ and $v$. Thus, the stabilized voltammogram at $0.04 \mathrm{~V} / \mathrm{s}$ of pc rhodium after applying a RTPS at $800 \mathrm{~V} / \mathrm{s}(f=0.25 \mathrm{kHz})$ between $E_{\mathrm{s}, \mathrm{c}}=0 \mathrm{~V}$ and $E_{\mathrm{s}, \mathrm{a}}=1.60 \mathrm{~V}$ for $30 \mathrm{~s}$ (Fig. 1b) shows a substantial increase in the voltammetric charge related to the H-adatom monolayer [16], i.e. from 320 to $500 \mu \mathrm{C} / \mathrm{cm}^{2}$ geometric area, and an increase in the sharpness of the $\mathrm{H}$-adatom peaks.

The stabilized voltammogram at $0.04 \mathrm{~V} / \mathrm{s}$ is accomplished after the fourth cycle, and in this respect it is illustrative to observe the changes in voltammetric response over the first few cycles (Fig. 1c). The first potential scan run from $E_{\mathrm{s}, \mathrm{a}}$ to lower potentials shows a small cathodic current peak at ca. $1.25 \mathrm{~V}$, a cathodic current minimum at ca. $0.85 \mathrm{~V}$, and a remarkable and continuous cathodic current increase in the $\mathrm{H}$-adatom electroadsorption potential range. The latter contribution is mostly associated with the electroreduction of the oxide layer formed during the application of fast RTPS treatment. It is also clear that the complete electroreduction of the oxide layer requires another few potential scans to attain the corresponding stabilized voltammogram (Fig. 1b). These voltammetric changes become more remarkable on increasing the duration of the fast RTPS treatment.

Similar experiments carried out at the same $E_{\mathrm{s}, \mathrm{c}}, v$ and $t$, but by setting values of $E_{\mathrm{s}, \mathrm{a}}$ between 1.5 and $3.0 \mathrm{~V}$, show that after electroreduction of the oxide layer a

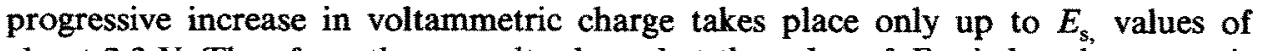
about $2.3 \mathrm{~V}$. Therefore, these results show that the value of $E_{\mathrm{s}, \mathrm{a}}$ is largely responsi- 


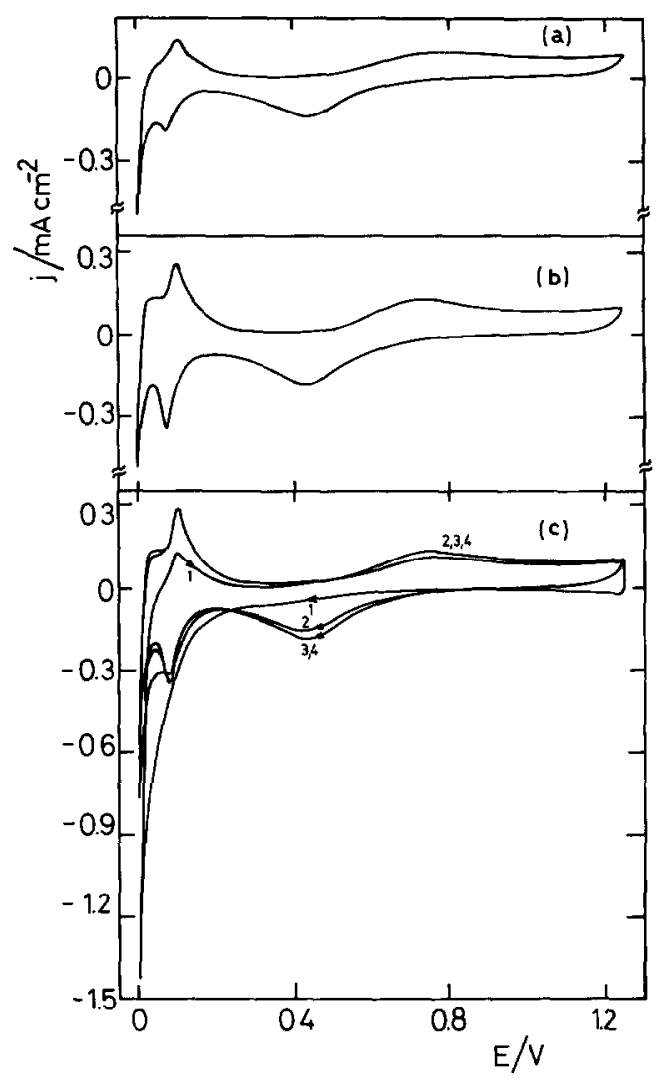

Fig. 1. Voltammograms for $\mathrm{Rh}$ (geometric area $0.7 \mathrm{~cm}^{2}$ ) in $1 M \mathrm{H}_{2} \mathrm{SO}_{4} \cdot v=0.04 \mathrm{~V} / \mathrm{s} ; 30^{\circ} \mathrm{C}$. (a) Blank. (b) Stabilized voltammogram (fourth scan) resulting after the RTPS treatment; $E_{\mathrm{s}, \mathrm{c}}=0 \mathrm{~V} ; E_{\mathrm{s}, \mathrm{a}}=1.60 \mathrm{~V}$, $f=0.25 \mathrm{kHz} ; t=30 \mathrm{~s}$. (c) Transition from the first negative potential scan to the stabilized voltammogram (fourth scan) after the RTPS treatment. The charge of the first negative potential scan is predominantly related to the electroreduction of the oxide layer formed during the RTPS treatment.

ble for the electroreduction behaviour of the anodic oxide layer produced by the fast RTPS.

Runs made at constant $E_{\mathrm{s}, \mathrm{c}}, E_{\mathrm{s}, \mathrm{a}}$ and $t$ show that the maximum change in the active electrode area resulting from the oxide layer electroreduction is accomplished for $v$ ranging from 100 to $1000 \mathrm{~V} / \mathrm{s}$. For values of $v>1000 \mathrm{~V} / \mathrm{s}$, the predominant effect is the increase in sharpness of the H-adatom current peaks. This effect is to some extent similar to that recently observed for the electrochemical faceting of pc rhodium in acids [4].

From these experiments one concludes that there is an optimal range of parameters defining the fast periodic potential to promote the growth of the oxide layer which, through its electroreduction, yields the increase in the active surface area of 
the rhodium electrode. These results furnish the basic conditions for attempting the application of other fast periodic potentials, such as RSWPS, to grow the anodic oxide layer. In this respect, it is worthwhile mentioning that from previous results obtained for platinum in acid [3] it was concluded that the actual shape of the fast periodic potential perturbation plays only a secondary role as compared to frequency and potential limits in promoting changes in the electrode surface characteristics.

The increase in active surface area through application of symmetric RSWPS

Application of a symmetric RSWPS to pc rhodium in $1 \mathrm{M} \mathrm{H}_{2} \mathrm{SO}_{4}$ for preset $E_{\mathrm{u}}$, $E_{1}$ and $f$ values promotes the growth of an oxide layer whose electroreduction charge greatly exceeds that expected for the O-monolayer. Potentiostatic electroreduction of the oxide layer yields an electroreduced rhodium surface which offers electrochemical characteristics slightly different from that of the blank and a remarkable increase in the surface area, as revealed from the increase in the voltammetric charge of either $\mathrm{H}$-adatom or $\mathrm{O}$-monolayer (Fig. 2).

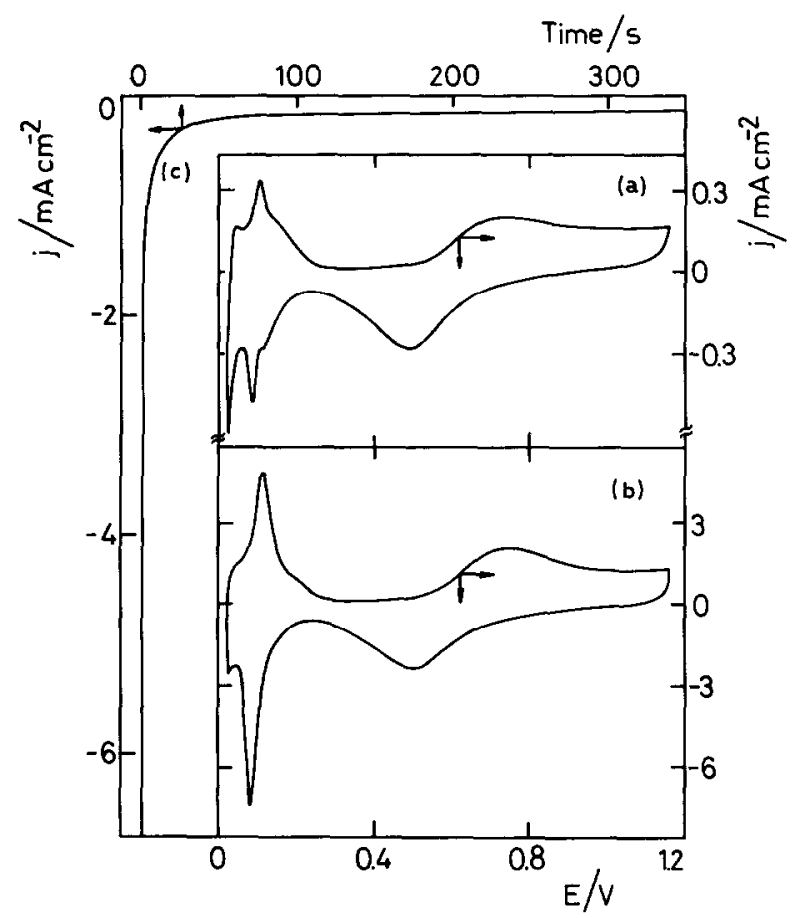

Fig. 2. Voltammograms for $\mathrm{Rh}$ (geometric area $0.07 \mathrm{~cm}^{2}$ ) in $1 \mathrm{M} \mathrm{H}_{2} \mathrm{SO}_{4} . v=0.1 \mathrm{~V} / \mathrm{s} ; 30^{\circ} \mathrm{C}$. (a) Blank. (b) Stabilized voltammogram after the RSWPS treatment; $E_{1}=0 \mathrm{~V} ; E_{\mathrm{u}}=2.1 \mathrm{~V} ; f=2.5 \mathrm{kHz} ; t=20 \mathrm{~s}$. (c) Cathodic transient response resulting for a potential jump from 2.1 to $0 \mathrm{~V}$. The integral charge is associated with the oxide layer electroreduction, without correction for residual oxygen electroreduction and hydrogen evolution contributions. 

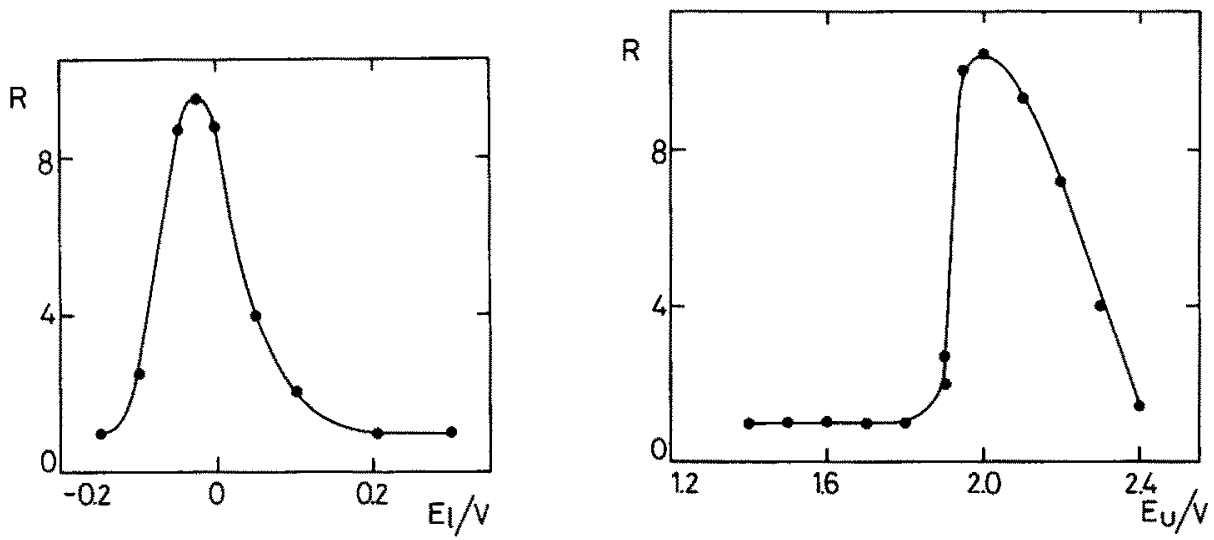

Fig. 3. Dependence of $R$ on $E_{1} . E_{\mathrm{u}}=2.0 \mathrm{~V} ; f=2.5 \mathrm{kHz} ; t=20 \mathrm{~s} ; 1 \mathrm{MH}_{2} \mathrm{SO}_{4} ; 30^{\circ} \mathrm{C}$.

Fig. 4. Dependence of $R$ on $E_{\mathrm{u}} . E_{1}=0 \mathrm{~V} ; f=2.5 \mathrm{kHz} ; t=20 \mathrm{~s} ; 1 \mathrm{MH}_{2} \mathrm{SO}_{4} ; 30^{\circ} \mathrm{C}$.

The relative increase in surface area $(R)$ can be defined as the quotient between the voltammetric charge related to the electroreduction of the surface oxide monolayer corresponding to treated rhodium $\left(Q_{\mathrm{t}}\right)$ to that of the blank $\left(Q_{0}\right)$, read at a constant $v$. For the symmetric RSWPS, the value of $R$ depends on $E_{\mathrm{u}}, E_{1}, f$ and $t$. At constant $E_{\mathrm{u}}, f$ and $t$, there is an optimal value of $E_{1}$ which lies close to $-0.025 \mathrm{~V}$ (Fig. 3 ), the corresponding dependence exhibiting a nearly bell-shape relationship. At constant $E_{\mathrm{l}}, f$ and $t$, the dependence of $R$ on $E_{\mathrm{u}}$ shows a relatively abrupt increase at $E_{\mathrm{u}}=$ ca. $1.9 \mathrm{~V}$, reaching a maximum value for $E_{\mathrm{u}}=2.0 \mathrm{~V}$ and decreasing to one for $E_{\mathrm{u}}>2.4 \mathrm{~V}$ (Fig. 4). The dependence of $R$ on $f$ (Fig. 5) shows
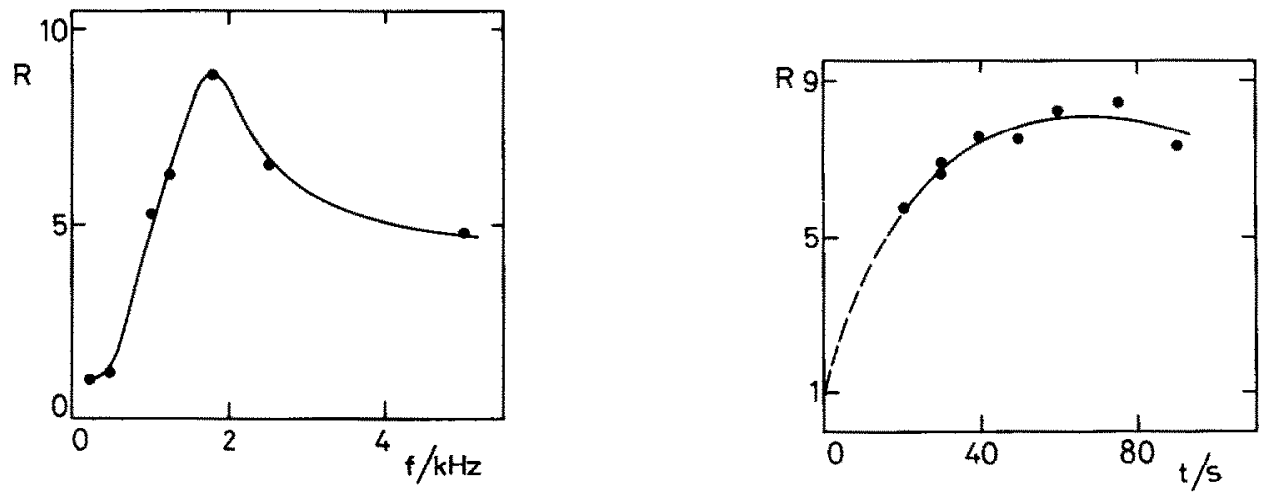

Fig. 5. Dependence of $R$ on $f$. $E_{1}=0 \mathrm{~V} ; E_{\mathrm{u}}=2.0 \mathrm{~V} ; t=20 \mathrm{~s} ; 1 \mathrm{MH}_{2} \mathrm{SO}_{4} ; 30^{\circ} \mathrm{C}$.

Fig. 6. Dependence of $R$ on $t . E_{1}=0 \mathrm{~V} ; E_{\mathrm{u}}=2.0 \mathrm{~V} ; f=2.5 \mathrm{kHz} ; 1 \mathrm{MH}_{2} \mathrm{SO}_{4} ; 30^{\circ} \mathrm{C}$. 


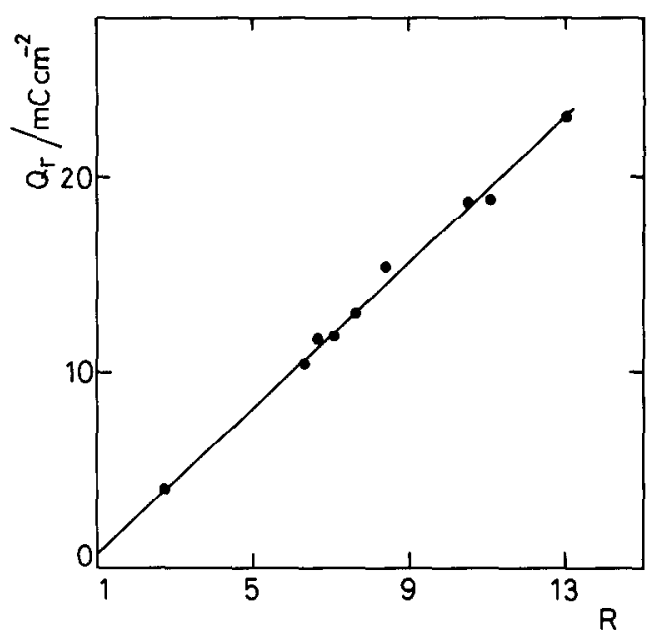

Fig. 7. Relationship between $Q_{\mathrm{r}}$ and $R$. $E_{1}=0 \mathrm{~V} ; E_{\mathrm{u}}=2.0 \mathrm{~V} ; f=2.5 \mathrm{kIIz} ; 1 \mathrm{M} \mathrm{H}_{2} \mathrm{SO}_{4} ; 30^{\circ} \mathrm{C}$. The value of $Q_{\mathrm{r}}$ extrapolated for $R=1$ coincides with that of an $O$-monolayer for an electrode with an initial roughness factor of ca. 1.6.

a threshold value for $f$ at ca. $0.5 \mathrm{kHz}$, then as $f$ increases, $R$ increases up to a maximum for $f=1.8 \mathrm{kHz}$. Finally, $R$ decreases slowly and continuously as $f$ is set beyond $1.8 \mathrm{kHz}$. For the symmetric RSWPS, the optimal increase in $R$ is obtained for the following set of parameters: $E_{1}=-0.025 \mathrm{~V}, E_{\mathrm{u}}=2.0 \mathrm{~V}$ and $f=1.8 \mathrm{kHz}$. At constant $E_{1}, E_{\mathrm{u}}$ and $f, R$ increases with $t$ to reach a maximum value close to 8 at about 70 s (Fig. 6).

\section{Potentiostatic electroreduction of the oxide layer formed through fast RSWPS}

The electroreduction profile of the oxide layer formed under fast RSWPS is characterized by a continuous current decrease, the entire process occurring in less than $300 \mathrm{~s}$ (Fig. 2c). The charge $\left(Q_{\mathrm{r}}\right)$ associated with the oxide layer produced under the optimal RSWPS conditions can be evaluated directly by integrating the corresponding potentiostatic electroreduction current transients. As would be expected, $R$ is directly proportional to $Q_{\mathrm{r}}$ (Fig. 7).

Potentiostatic growth of anodic oxide layers

In order to compare the increase in surface area obtained through the fast periodic potential treatment with the increase resulting from the electroreduction of anodic oxide layers formed under potentiostatic conditions, rhodium oxide layers were also obtained by holding the electrode potential at a constant value, $E_{\tau}$, in the range $1.5 \mathrm{~V} \leqslant E_{\tau} \leqslant 2.5 \mathrm{~V}$ for time values, $\tau$, from $30 \mathrm{~s}$ up to $30 \mathrm{~min}$. 


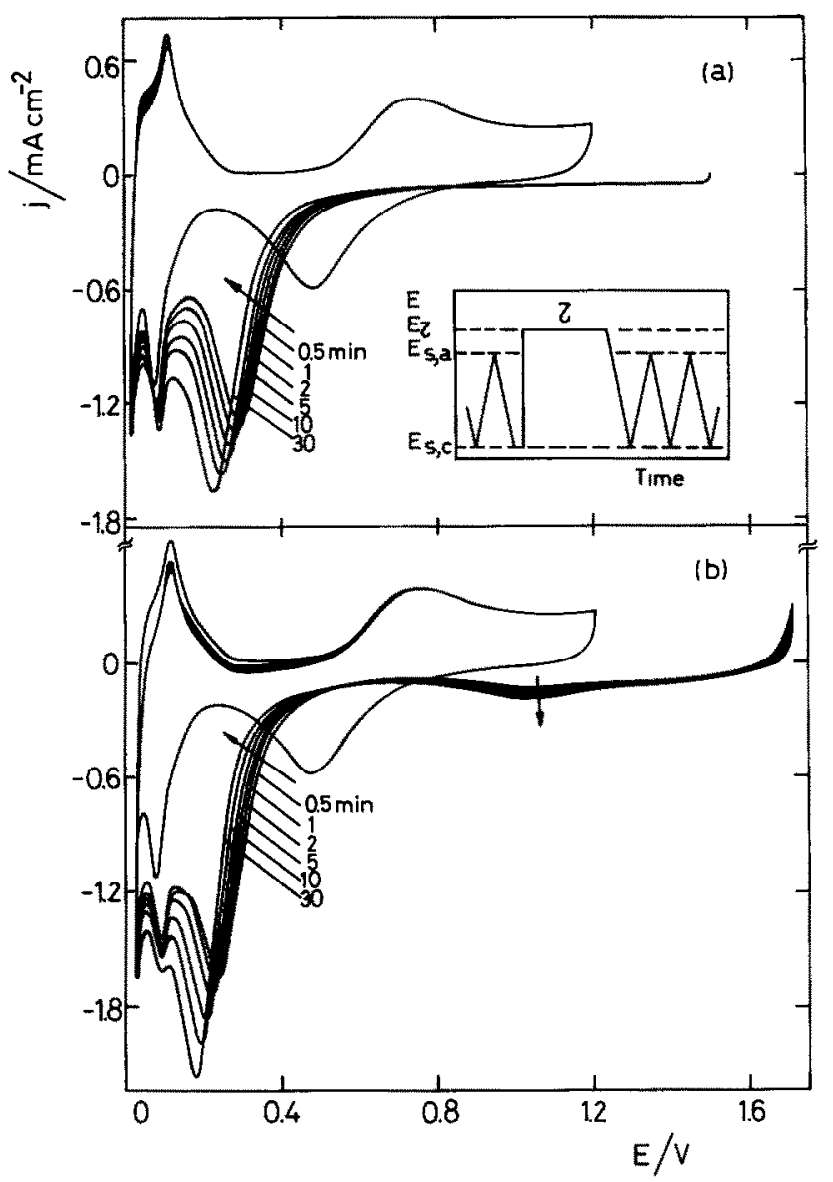

Fig. 8. Single negative scans at $0.2 \mathrm{~V} / \mathrm{s}$ in $1 \mathrm{M} \mathrm{H}_{2} \mathrm{SO}_{4}$ at $30^{\circ} \mathrm{C}$ starting after holding the electrode (geometric area $0.12 \mathrm{~cm}^{2}$ ) at $E_{\tau}=1.5 \mathrm{~V}$ (a) and $1.7 \mathrm{~V}$ (b) for different times in the $0.5-30$ min range. The following voltammograms run between 0.03 and $1.2 \mathrm{~V}$ at $0.2 \mathrm{~V} / \mathrm{s}$ coincide with the blank. The potential/time perturbation programme is included in the figure.

For $E_{\tau} \leqslant 1.5 \mathrm{~V}$ in $1 \mathrm{M} \mathrm{H}_{2} \mathrm{SO}_{4}$, the electroreduction potential scan exhibits a current peak in the 0.1-0.4 V range. Furthermore, there is an increase in the electroreduction charge according to $\tau$, up to an apparent limiting value which is about twice the charge of the electroreduction peak at ca. $0.475 \mathrm{~V}$ in the voltammogram at $0.2 \mathrm{~V} / \mathrm{s}$ covering from $1.2 \mathrm{~V}$ down to $0.03 \mathrm{~V}$ (Fig. 8a). It should be noted that as $\tau$ increases, the potential range for electroreducing the layer is shifted towards more negative potentials and simultaneously, the corresponding charge is increased. In this case, after the complete electroreduction of the anodic oxide layer, the corresponding stabilized voltammogram coincides with that of the blank; that is, no appreciable increase in active surface area is noticed. It should be emphasized 


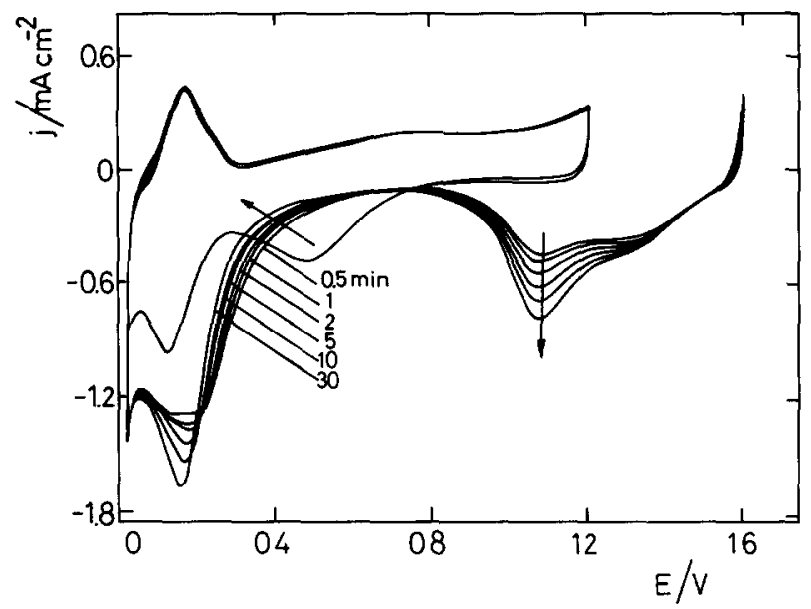

Fig. 9. Voltammetric results similar to those described in Fig. 8 run in $1 \mathrm{M} \mathrm{NaOH}$ at $30^{\circ} \mathrm{C} . E_{\tau}=1.6 \mathrm{~V}$.

that the electroreduction characteristics of this oxide layer differ from those resulting from the fast periodic perturbation treatment.

On subsequent increase of $E_{\tau}$ from $1.6 \mathrm{~V}$ up to $2.5 \mathrm{~V}$, the overall electroreduction charge increases according to $E_{\tau}$ and $\tau$, and the electroreduction scan begins to exhibit a wide peak at ca. $1.025 \mathrm{~V}$ extending from nearly $1.4 \mathrm{~V}$ down to $0.8 \mathrm{~V}$ (Fig. $8 b)$ followed by another one in the 0.1-0.4 V range which is apparently similar to that shown in Fig. 8a. For constant $\tau$, the corresponding peak potential becomes more negative as the value of $E_{\tau}$ is set more positive. Therefore, for $1.6 \mathrm{~V} \leqslant E_{\tau} \leqslant 2.5$ $\mathrm{V}$ it appears that at least two different types of oxide are formed, namely, one related to the peak at ca. $1.025 \mathrm{~V}$ and the other associated with the peak at ca. $0.2-0.3 \mathrm{~V}$. Similar results are obtained in $1 \mathrm{M} \mathrm{HClO}_{4}$, although in this case the voltammogram involves relatively broader peaks than those in $1 \mathrm{M} \mathrm{H}_{2} \mathrm{SO}_{4}$.

On the other hand, runs made in $1 M \mathrm{NaOH}$ are qualitatively comparable to those made in acids (Fig. 9). In a base solution, however, for $1.5 \mathrm{~V} \leqslant E_{\tau} \leqslant 1.6 \mathrm{~V}$, the electroreduction profile exhibits a clear double peak in the $0.8-1.4 \mathrm{~V}$ range, their relative contributions depending also on $E_{\tau}$ and $\tau$. Furthermore, for $\tau<5 \mathrm{~min}$, the electroreduction of the anodic layer is also associated with the contribution of two peaks in the 0.1-0.4 V range, but for $\tau>5 \mathrm{~min}$, only a single electroreduction peak is recorded. These results also indicate that various types of oxide are formed at $E_{\tau}$ in a base electrolyte although these oxides cannot be compared straightforwardly to those already described for acids. It should be noted that in $1 M \mathrm{NaOH}$ for $E_{\tau}>1.6$ $\mathrm{V}$, only single electroreduction peaks in the $0.1-0.4 \mathrm{~V}$ and $0.8-1.4 \mathrm{~V}$ ranges are observed for potentiostatically formed anodic layers.

Otherwise, either in acid or in base, for any $E_{\tau}$ value, once the electroreduction of potentiostatically formed oxide layers has been completed, the voltammetric charge at $0.2 \mathrm{~V} / \mathrm{s}$ differs by only a few per cent from the initial one. Therefore, 
these results confirm that the oxide layers grown under potentiostatic conditions are not able to produce an increase in the electrode surface area through their electroreduction. The voltammetric behaviour of these oxide layers resembles the behaviour of those produced in an acid under high potential step conditions $[16,19]$, as well as the behaviour of those resulting through either potentiodynamic or potentiostatic ageing teclmiques $[17,18]$.

\section{DISCUSSION}

Some general remarks about the growth of rhodium oxide layers

The macroscopic growth of anodic oxide layers on pc rhodium which are adequate for furnishing an increase in the active electrode area after their electroreduction requires the application of a periodic perturbing potential between preset upper $\left(E_{\mathrm{u}}\right.$ or $\left.E_{\mathrm{s}, \mathrm{a}} \leqslant 2.3 \mathrm{~V}\right)$ and lower $\left(E_{1}\right.$ or $\left.E_{\mathrm{s}, \mathrm{c}} \simeq 0 \mathrm{~V}\right)$ potential limits at a frequency exceeding a certain threshold value. On the other hand, when the formation of the oxide layer is accomplished by applying either a periodic potential with $E_{\mathrm{u}}$ or $E_{\mathrm{s}, \mathrm{a}}>2.3 \mathrm{~V}$, or a constant potential step in the $1.5-2.5 \mathrm{~V}$ range, the thickness of the oxide layer involves only a few monolayers. Therefore, these layers produce no appreciable increase in the electrode surface roughness after their electroreduction.

For a better understanding of the matter, each situation is considered separately in the following sections.

\section{Electrochemical treatment yielding a net increase in the active electrode area}

(i) The formation of the anodic oxide layer

The most significant increases in the active surface area of rhodium electrodes were obtained from electroreduction of oxide layers formed by application of the RSWPS technique under the following conditions: $1.9 \mathrm{~V} \leqslant E_{\mathrm{u}} \leqslant 2.3 \mathrm{~V} ;-0.1$ $\mathrm{V} \leqslant E_{1} \leqslant 0.1 \mathrm{~V} ; 0.5 \mathrm{kHz} \leqslant f \leqslant 6 \mathrm{kHz}$. These figures, in principle, indicate that the average potential during the application of the fast periodic potential is more positive than the equilibrium potentials of those redox reactions involving different rhodium species such as $\mathrm{Rh}(\mathrm{s}), \mathrm{Rh}^{+}(\mathrm{aq}), \mathrm{Rh}^{2+}(\mathrm{aq}), \mathrm{Rh}^{3+}$ (aq), $\mathrm{Rh}_{2} \mathrm{O}, \mathbf{R h O}, \mathbf{R h}_{2} \mathrm{O}_{3}$ and $\mathrm{RhO}_{2}$ [20]. Under the above-mentioned RSWPS conditions, one would expect a net balance favouring the electrooxidation of rhodium and the accumulation of a rhodium oxide layer.

According to previously reported data [17,18], the electrooxidation process is initiated through the formation of electroadsorbed $\mathrm{OH}$ species as indicated by the reaction

$\mathrm{Rh}+\mathrm{H}_{2} \mathrm{O}=\mathrm{Rh}(\mathrm{OH})_{\mathrm{ad}}+\mathrm{H}^{+}+e^{-}$

Reaction (1) corresponds to the reversible underpotential decomposition of water on rhodium occurring in acids at potentials as low as $0.5 \mathrm{~V}[16,17]$. It is also known 
that during potential cycling of noble metal electrodes in an acid, there is a measurable participation of the electrodissolution reaction [16,21]. This means that part of the $\mathrm{Rh}(\mathrm{OH})_{\mathrm{ad}}$ can be oxidized further as follows:

$\mathrm{Rh}(\mathrm{OH})_{\mathrm{ad}}+\mathrm{H}^{+} \rightarrow \mathrm{Rh}^{3+}(\mathrm{aq})+\mathrm{H}_{2} \mathrm{O}+2 e^{-}$

According to reactions (1) and (2), the positive half-cycle produces two species at the reaction interface. Likewise, the duration of the positive half-cycle must be shorter than $1 \mathrm{~ms}$ in order to effect growth of the oxide layer. This time is close to or slightly smaller than the half-life time of the $\mathrm{Rh}(\mathrm{OH})_{\mathrm{ad}}$ species $[17,18]$, so that any reaction of the latter implying a further irreversible deprotonation and simultaneous formation of more stable surface oxide species, such as ageing processes $[17,18]$, can be neglected. As it occurs with other metals $[5,6,22,23]$, it is likely that the growth of the anodic oxide layer under fast periodic potentials involves only hydrous forms of rhodium hydroxide. In this respect, from a comparison of the binding energies of the electrons at the $\mathrm{O} 1 \mathrm{~s}$ level for rhodium-oxygen and platinum-oxygen compounds [24] and those species formed on rhodium and platinum after anodic polarization, derived from X-ray electron and Auger spectroscopy [25], it was concluded that the anodically formed layers on rhodium as well as those on platinum are hydrous layers and that the degree of water content increases with approach to the surface [25]. Furthermore, on the basis of the structure of Rh(III) anodic layers formed on rhodium in acids derived from XPS studies [26], the formation of the anodic oxide layer under RSWPS in the 1.9 $\mathrm{V} \leqslant E_{\mathrm{u}} \leqslant 2.3 \mathrm{~V}$ range can be interpreted in terms of a series of reactions yielding different hydrous $\mathrm{Rh}(\mathrm{OH})_{x}$ species starting with $x=1$, and finally forming a hydrous Rh(III) hydroxide species. Hence, the reaction sequence can be written formally as follows:

$$
\begin{aligned}
& \mathrm{Rh}+\mathrm{H}_{2} \mathrm{O}=\mathbf{R h}(\mathrm{OH})_{\mathrm{ad}}+\mathrm{H}^{+}+e^{-} \\
& \begin{array}{r}
\underset{+\mathrm{H}_{2} \mathrm{O}}{\longrightarrow} \mathrm{Rh}(\mathrm{OH})_{2}+\mathrm{H}^{+}+e^{-} \\
\underset{+\mathrm{H}_{2} \mathrm{O}}{\longrightarrow} \mathrm{Rh}(\mathrm{OH})_{3}+\mathrm{H}^{+}+e^{-} \\
\underset{+\mathrm{H}_{2} \mathrm{O}}{\longrightarrow} \mathrm{RhOOH} \cdot n \mathrm{H}_{2} \mathrm{O}
\end{array}
\end{aligned}
$$

According to the reaction sequence (3a)-(3d), the electroreduction half-cycle during the RSWPS should involve mainly reaction (3a) in the reverse direction and a partial contribution of reactions (3b)-(3d) through a reversible displacement of $\mathrm{H}^{+}$ ions and $\mathrm{H}_{2} \mathrm{O}$ molecules. In addition, it should be mentioned that $\mathrm{Rh}$ (III) oxides can also be produced during the electroreduction half-cycle at potentials lower than $0.4 \mathrm{~V}$ due to the partial contribution of a local alkalinization effect related to $\mathrm{H}$-adatom formation in the presence of soluble $\mathrm{Rh}$ (III) species inserted in the oxide layer. The corresponding global reaction can be written formally as follows:

$\mathrm{Rh}^{3+}+3 \mathrm{H}_{2} \mathrm{O}+3 e^{-} \rightarrow \mathrm{Rh}(\mathrm{OH})_{3}+3(\mathrm{H})_{\mathrm{ad}}$

This type of reaction is very well known for a large number of metals [10,23]. 
Furthermore, minor quantities of oxygen produced at $E_{\mathrm{u}} \geqslant 2 \mathrm{~V}$ can also contribute, during the negative half-cycle and in the presence of soluble Rh(III) species at the interface, to the oxide layer growth through an overall reaction such as

$4 \mathrm{Rh}^{3+}+3 \mathrm{O}_{2}+6 \mathrm{H}_{2} \mathrm{O}+2 e^{-} \rightarrow 4 \mathrm{Rh}(\mathrm{OH})_{3}$

Therefore, the fast periodic potential treatment, either RSWPS or RTPS, under the suitable conditions already mentioned yields a rhodium electrode covered with a relatively thick hydrous $\mathbf{R h}$ (III) oxide layer.

(ii) The large active surface area rhodium resulting from the oxide layer electroreduction

The hydrous oxide layer formed as described in the previous section can be electroreduced to metallic rhodium in the $\mathrm{H}$-adatom electroadsorption potential range, yielding a large increase in the active surface area. The formal stoichiometric reaction for the electroreduction process can be written as

$\mathrm{RhOOH} \cdot n \mathrm{H}_{2} \mathrm{O}+3 \mathrm{H}^{+}+3 e^{-}=\mathrm{Rh}^{*}+(n+2) \mathrm{H}_{2} \mathrm{O}$

where $\mathrm{Rh}^{*}$ denotes the electroreduced rhodium layer. The voltammetric response of the resulting surface shows an increase in the sharpness and symmetry of the $\mathrm{H}$-electrosorption peaks approaching that resulting for (111)-faceted rhodium electrodes in the same electrolyte [4]. Furthermore, similarly to large surface area electroreduced platinum and gold [5-7], the new electrode surface exhibits no diffusion relaxation and ohmic contribution loss for electrochemical reactions under conventional voltammetric conditions. The structure of these surfaces, as has recently been elucidated from scanning electron tunnelling microscopy $[27,28]$, consists of an overlayer of sphere-like adhering metal clusters of about $10 \mathrm{~nm}$ average radius, with inner channels of about the same size and extending in depth.

The anodic oxide layer formation under either fast periodic potentials for $E_{u}>2.3 \mathrm{~V}$ or potentiostatic conditions

The electrochemical treatment with a fast periodic potential for $E_{\mathrm{u}}>2.3 \mathrm{~V}$ yields an anodic oxide layer which after electroreduction is poorly effective in yielding an active surface area increase. The phenomenon is presumably related to a loss of water from the hydrous oxide layer favoured through the oxygen evolution reaction (OER) [22,23], the rate of the latter increasing exponentially with the applied potential. This reaction can be written formally as follows:

$\mathrm{RhOOH} \cdot n \mathrm{H}_{2} \mathrm{O} \rightarrow \mathrm{RhOOH} \cdot(n-2) \mathrm{H}_{2} \mathrm{O}+\mathrm{O}_{2}+4 \mathrm{H}^{+}+4 e^{-}$

or alternatively:

$2\left[\mathrm{RhOOH} \cdot n \mathrm{H}_{2} \mathrm{O}\right] \rightarrow \mathrm{Rh}_{2} \mathrm{O}_{3} \cdot n^{\prime} \mathrm{H}_{2} \mathrm{O}+n^{\prime \prime} \mathrm{H}_{2} \mathrm{O}+\mathrm{O}_{2}+4 \mathrm{H}^{+}+4 e^{-}$ where $(n-2)=n^{\prime}+n^{\prime \prime}$. 
In addition, it should be noted that the equilibrium potential for the reaction

$\mathrm{Rh}_{2} \mathrm{O}_{3}+\mathrm{H}_{2} \mathrm{O}=2 \mathrm{RhO}_{2}+2 \mathrm{H}^{+}+2 e^{-}$

is $1.73 \mathrm{~V}$ [20]. These reactions would imply a final stabilization of the rhodium oxide layer either as $R h(I I I)$ or $R h(I V)$ species. $R h(I I I)$ and $R h(I V)$ oxide species have actually been identified and isolated as bulk oxides [20], although at present there is no clear evidence for $\mathrm{Rh}(\mathrm{IV})$ species at the electrochemical interphase [26]. Hence, reactions (7a) or (7b) and (8) must hinder the possibility of attaining the hydrous structure required for the increase in active surface area. A similar explanation can be applied to the rhodium oxide layers formed under conventional potentiostatic conditions where ageing effects act in the same direction as the OER in forming stabilized oxide species.

\section{CONCLUSIONS}

The active surface area of rhodium electrodes can be increased in a reproducible and controllable way through electroreduction of a relatively thick hydrous oxide layer produced by fast periodic potentials of suitable characteristics, in a manner which is qualitatively comparable to that already described for gold and platinum in acid solutions. The resulting surfaces are very stable, even to different electrooxidation/electroreduction cycles, and exhibit voltammograms in the $\mathrm{H}$ - and $\mathrm{O}$-adatom potential range without distortion for potential sweep rates as high as $1 \mathrm{~V} / \mathrm{s}$.

\section{ACKNOWLEDGEMENTS}

This work was supported financially by the Consejo Nacional de Investigaciones Científicas y Técnicas and the Comisión de Investigaciones Científicas de la Provincia de Bucnos Aircs. It was also partially supported by the Regional Program for the Scientific and Technological Development of the Organization of American States.

\section{REFERENCES}

1 A.J. Arvia, J.C. Canullo, E. Custidiano, C.L. Perdriel and W.E. Triaca, Electrochim. Acta, 31 (1986) 1359.

2 R.M. Cerviño, W.E. Triaca and A.J. Arvia, J. Electroanal. Chem., 182 (1985) 51.

3 W.E. Triaca, T. Kessler, J.C. Canullo and A.J. Arvia, J. Electrochem. Soc. 134 (1987) 1165.

4 E. Custidiano, A.C. Chialvo, S.M. Piovano, M. Ipohorski and A.J. Arvia, J. Electroanal. Chem., 221 (1987) 229.

5 A.C. Chialvo, W.E. Triaca and A.J. Arvia, J. Electroanal. Chem., 146 (1983) 93.

6 A.C. Chialvo, W.E. Triaca and A.J. Arvia, J. Electroanal. Chem., 171 (1984) 303.

7 S.M. Piovano, A.C. Chialvo, W.E. Triaca and A.J. Arvia, J. Appl. Electrochem., 17 (1987) 147.

8 T. Kessler, A.M. Castro Luna, W.E. Triaca and A.J. Arvia, J. Appl. Electrochem., 16 (1986) 693.

9 A. Visintin, W.E. Triaca and A.J. Arvia, J. Electroanal. Chem., 221 (1987) 235.

10 L.D. Burke and E.J.M. O'Sullivan, J. Electroanal. Chem., 93 (1978) 11.

11 O.A. Petrii in A.N. Frumkin and A.B. Ershler (Eds.), Progress in Electrochemistry of Organic Compounds, Plenum Press, London, 1971, p. 319. 
12 P.N. Ross, K. Kinoshita, A.J. Scarpellino and P. Stonehart, J. Electroanal. Chem., 59 (1975) 177.

13 J. Sobkowski and P. Zelenay, J. Electroanal. Chem., 91 (1978) 309.

14 J. Sobkowski, A. Wieckowski, P. Zelenay and A. Czerwinski, J. Electroanal. Chem., 100 (1979) 781.

15 N.R. de Tacconi, J.M. Leger, B. Beden and C. Lamy, J. Electroanal. Chem., 134 (1982) 117.

16 R. Woods in A.J. Bard (Ed.), Electroanalytical Chemistry, Vol. 9, Marcel Dekker, New York, 1976, p. 90.

17 C. Pallotta, N.R. de Tacconi and A.J. Arvia, Electrochim. Acta, 26 (1981) 261.

18 C. Pallotta, N.R. de Tacconi and A.J. Arvia, J. Electroanal. Chem., 159 (1983) 201.

19 D.A.J. Rand and R. Woods, J. Electroanal. Chem., 31 (1971) 29.

20 A.J. Bard, R. Parsons and J. Jordan (Eds.), Standard Potentials in Aqueous Solution, Marcel Dekker, New York, 1985.

21 A.E. Bolzán, M.E. Martins and A.J. Arvia, J. Electroanal. Chem., 157 (1983) 339.

22 L.D. Burke and T.A.M. Twomey, J. Electroanal. Chem., 162 (1984) 101.

23 A. Visintin, A.C. Chialvo, W.E. Triaca and A.J. Arvia, J. Electroanal. Chem., 225 (1987) 227.

24 T.L. Barr, J. Phys. Chem., 82 (1978) 1801.

25 A.A. Yakovleva, I.L. Kubinova, A.M. Kleshchevnikov, E.N. Lubnin and Ya.M. Kolotyrkin, Sov. Electrochem., 20 (1984) 374.

26 M. Peuckert, Surf. Sci., 141 (1984) 500.

27 L. Vásquez, J. Gómez, A.M. Baró, N. García, M.L. Marcos, J. González Velasco, J.M. Vara Cuadrado, A.J. Arvia, J. Presa, A. García and M. Aguilar, J. Am. Chem. Soc., 109 (1987) 1730.

28 J. Gómez, L. Vázquez, A.M. Baró, C. Alonso, E. González, J. Gónzalez-Velasco and A.J. Arvia, J. Electroanal. Chem., in press. 